\title{
ГИБРИДНЫЕ ЭЛЕКТРОМАГНИТНО-СПИНОВЫЕ КОЛЕБАНИЯ В ФЕРРИТ-ДИЭЛЕКТРИЧЕСКОЙ СТРУКТУРЕ С МОНОКРИСТАЛЛИЧЕСКИМ ГЕКСАФЕРРИТОМ В ДОМЕННОЙ ОБЛАСТИ
}

\author{
НИКИТЕНКО А. Л., ГРИГОРУК В. И., КОСТЕНКО В. И., СОРОЧАК А. М., ЧЕВНЮК Л. В.
}

Киевский национальный университет имени Тараса Шевченко,

Украина, Киев, 01601, ул. Владимирская, 64/13

\begin{abstract}
Аннотация. Экспериментально исследованы гибридные электромагнитно-спиновые колебания в феррит-диэлектрической структуре, состоящей из монокристаллической пластинки $\mathrm{BaFe}_{12} \mathrm{O}_{19}$ и диэлектрического резонатора в форме диска, в многодоменном состоянии феррита. Эксперименты проводились с различными типами доменных структур, частотно-полевые спектры измерены при касательном намагничивании. Показано, что эффективная гибридизация электромагнитных и магнитостатических мод в таком резонаторе может реализовать режим возбуждения, при котором одна электромагнитная мода диэлектрического резонатора расщепляется на три гибридных квазиэлектромагнитных колебания даже в отсутствии внешних полей намагничивания.
\end{abstract}

Ключевые слова: монокристаллический гексаферрит; гибридные электромагнитно-спиновые колебания; составная феррит-диэлектрическая структура; частотно-полевая зависимость; доменная структура

\section{ВВЕДЕНИЕ}

Ферритовые резонаторы известны своими уникальными магнитными свойствами достаточно давно, однако потребность в детальном изучении их высокочастотных характеристик сегодня как никогда актуальна. В наше время тенденции развития новейших систем беспроводной связи демонстрируют растущий интерес к освоению диапазона радиоволн миллиметрового диапазона (мм-диапазон), при неизменном условии миниатюризации и энергоэффективности [1].

В связи с этим, в значительной степени актуализировалась потребность в инновационных разработках эффективных гибридных интегрально-планарных СВЧ-схем этого диапазона, при этом существенное значение приобретает применение в них композитных, слоистых феррит-диэлектрических структур, по- зволяющих расширить их функциональные возможности. Успех выполнения поставленных практических задач напрямую зависит от экспериментальных исследований особенностей магнитных материалов и структур на их основе в мм-диапазоне частот.

Значительный научный и практический интерес представляет собой исследование монокристаллического бариевого гексаферрита $\mathrm{BaFe}_{12} \mathrm{O}_{19}$ и структур на его основе. Данный материал имеет поле кристаллографической анизотропии $H_{\mathrm{a}}$ порядка 17 кЭ и устойчивую регулярную доменную структуру (ДС) определенного типа в размагниченном состоянии, что делает возможным его использование в качестве резонансного элемента функциональной электроники как при малых внешних полях намагничивания $H_{0}$, так и при отсутствии приложенного магнитного поля. 
Гибридные электромагнитно-спиновые колебания в феррит-диэлектрической структуре с монокристаллическим гексаферритом в доменной области

\section{БИБЛИОГРАФИЧЕСКИЙ СПИСОК}

1. Maccartney G. R. Millimeter-wave omnidirectional path loss data for small cell 5G channel modeling / George R. MacCartney, Jr., Theodore S. Rappaport, Mathew K. Samimi, Shu Sun // IEEE Access. - 2015. Vol. 3. - P. 1573-1580. - DOI : 10.1109/ACCESS.2015.2465848. 
2. Demidov V. E. Dipole-exchange theory of hybrid electromagnetic-spin waves in layered film structures / V. E. Demidov, B. A. Kalinikos // J. Appl. Phys. - 2002. Vol. 91, No. 12. - P. 10007-10016. - DOI : 10.1063/1.1475373.

3. Electric field tunable $60 \mathrm{GHz}$ ferromagnetic resonance response in barium ferrite-barium strontium titanate multiferroic heterostructures / Young-Yeal Song, Jaydip Das, Pavol Krivosik, Nan Mo, Carl E. Patton // Appl. Phys. Lett. — 2009. — Vol. 94. - P. 182505 . DOI : $10.1063 / 1.3131042$.

4. Coupled magnetostatic and electromagnetic oscillations in hexaferrite-dielectric heterostructures / Maksym A. Popov, Igor V. Zavislyak, Gopalan Srinivasan, Volodymyr V. Zagorodnii // J. Appl. Phys. — 2009. Vol. 105. - P. 083912. — DOI : 10.1063/1.3108895.

5. Coupled ferrite-dielectric resonances in epitaxial barium ferrite films / I. V. Zavislyak, V. I. Kostenko, T. G. Chamor, L. V. Chevnyuk // Magnetism M. V. Lomonosov Moscow State University : Moscow Int. Symp. MisM, 2005, Moscow, Russia : proc. — 2005. - P. 604-605.
6. Гибридные электромагнитно-спиновые колебания в слоистых структурах с одноосными гексаферритами / В. И. Костенко, А. М. Сорочак, Т. Г. Чамор, Л. В. Чевнюк // Журн. техн. физ. - 2011. — Т. 81, № 5. - С. 40-43. - Режим доступа : http://journals.ioffe.ru/articles/10300.

7. Ильченко M. E. Ферритовые и диэлектрические резонаторы СВЧ / М. Е. Ильченко, Е. В. Кудинов. К. : Изд. Киевского университета, 1973. - 175 с.

8. Kostenko V. I. Magnetostatic waves in a thin uniaxial platelet with stripe domains magnetized along the easy axis / V. I. Kostenko, M. A. Sigal // Phys. Stat. Sol. (B). - Apr. 1992. — Vol. 170, No. 2. - P. 569-584. DOI : $10.1002 /$ pssb.2221700222.

9. Sigal M. A. Magnetostatic modes in a thin uniaxial platelet with bubble lattice at normal magnetization / M. A. Sigal, V. I. Kostenko // Phys. Stat. Sol. (A). - Nov. 1991. - Vol. 128, No. 1. - P. 219-234. - DOI : 10.1002/pssa.2211280125.

Поступила в редакцию ? По-сле переработки ? 